
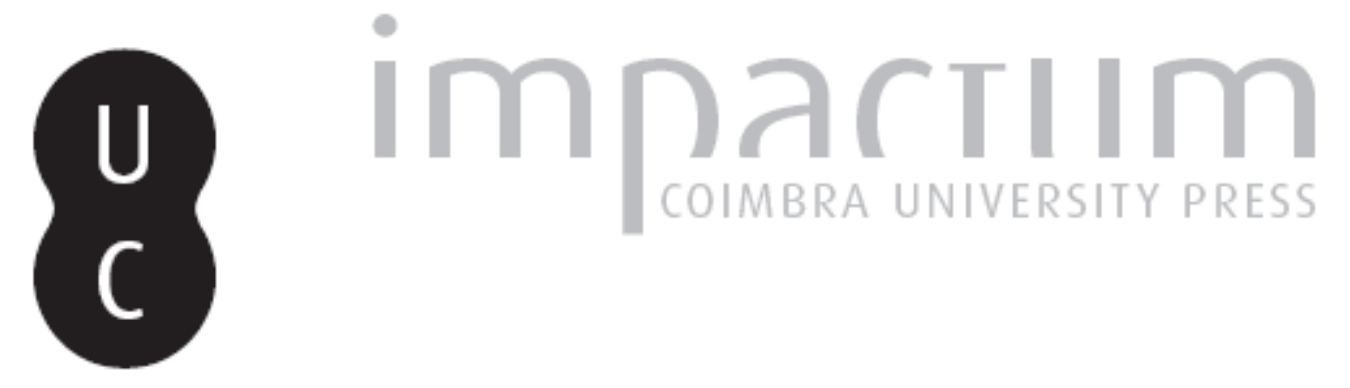

\title{
Los pasaportes internos como fuente para el estudio de la emigración gallega al norte de Portugal (1700-1850)
}

\author{
Autor(es): $\quad$ Fernández Cortizo, Camilo J.
}

Publicado por: Centro de História da Sociedade e da Cultura

URL persistente:

URI:http://hdl.handle.net/10316.2/39528

DOI:

DOI:http://dx.doi.org/10.14195/1645-2259_10-2_2

Accessed : $\quad$ 26-Apr-2023 10:21:47

A navegação consulta e descarregamento dos títulos inseridos nas Bibliotecas Digitais UC Digitalis, UC Pombalina e UC Impactum, pressupõem a aceitação plena e sem reservas dos Termos e Condições de Uso destas Bibliotecas Digitais, disponíveis em https://digitalis.uc.pt/pt-pt/termos.

Conforme exposto nos referidos Termos e Condições de Uso, o descarregamento de títulos de acesso restrito requer uma licença válida de autorização devendo o utilizador aceder ao(s) documento(s) a partir de um endereço de IP da instituição detentora da supramencionada licença.

Ao utilizador é apenas permitido o descarregamento para uso pessoal, pelo que o emprego do(s) título(s) descarregado(s) para outro fim, designadamente comercial, carece de autorização do respetivo autor ou editor da obra.

Na medida em que todas as obras da UC Digitalis se encontram protegidas pelo Código do Direito de Autor e Direitos Conexos e demais legislação aplicável, toda a cópia, parcial ou total, deste documento, nos casos em que é legalmente admitida, deverá conter ou fazer-se acompanhar por este aviso.

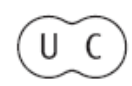




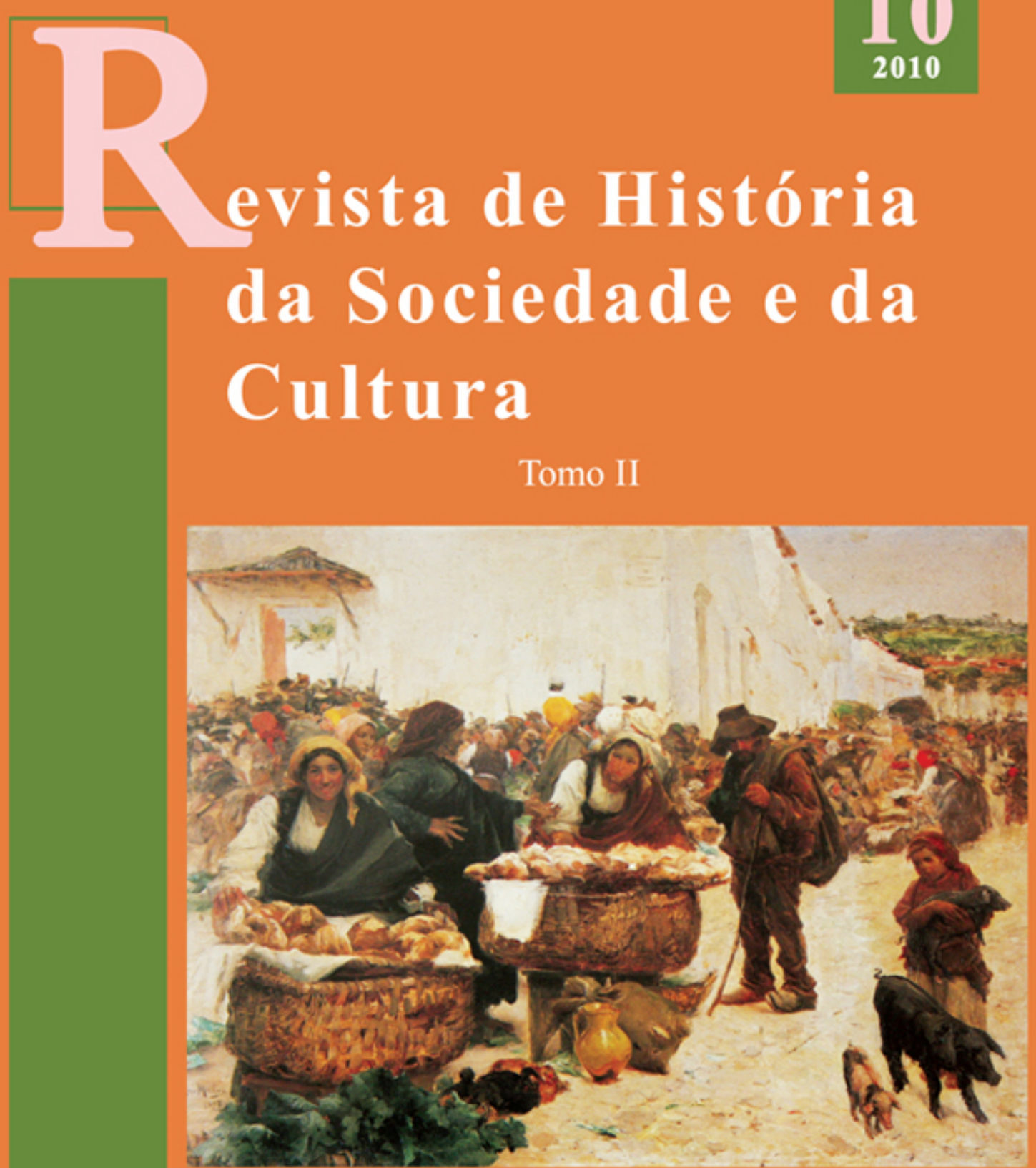

Centro de História da Sociedade e da Cultura Universidade de Coimbra

Coimbra 


\title{
Los pasaportes internos como fuente para el estudio de la emigración gallega al norte de Portugal (1700-1850)
}

\author{
Camilo J. Fernández Cortizo \\ Departamento de Historia Medieval y Moderna, Universidad de Santiago de Compostela \\ camilojesus.fernandez@usc.es \\ Texto recebido em/ Text submitted on: 08/09/2009 \\ Texto aprovado em/ Text approved on: 01/02/2010
}

\section{Resumo/Abstract:}

A investigação sobre a emigração galega para o Norte de Portugal tem conquistado, desde os anos 1990, o interesse de um crescente, embora ainda reduzido, número de historiadores portugueses e galegos; os factores que explicam este novo impulso são certamente vários, um dos quais, de inegável influência, foi a consulta de um corpo mais alargado e diversificado de fontes documentais de arquivos, tanto portugueses como galegos, de resto nada ou muito pouco exploradas até à data. Entre estas fontes encontramos os passaportes internos que, pese a sua implantação temporal tardia (1760), a sua conservação descontínua até à supressão (1863) e a falta de homogeneidade dos seus registos, são sem dúvida o fundo documental com a informação mais plural sobre emigrantes galegos, permitindo conhecer aspectos tão variados como a localidade de origem e de destino, duração da viagem ou de permanência, actividade profissional, sexo, idade, estado, etc. Assim, o seu contributo, em complementaridade com o de outras fontes de natureza diversa (arquivos paroquiais, registos hospitalares, livros de contas das alfândegas, etc.), tem-se revelado imprescindível na mais recente investigação sobre a emigração galega para Portugal e na ampliação espacial da área de estudo, agora já estendida desde o litoral minhoto a Trás-os-Montes e Alto Douro.

Since the 1990s, a growing - albeit reduced - number of Portuguese and Galician researchers have studied emigration flows from Galicia to north Portugal; there are certainly several explanations for this new impulse, one of which of undeniable influence was the extended and diversified body of documents retrieved from both Portuguese and Galician archives, until recently hardly used or largely unexplored. These resources include national passports which, although implemented late in history (1760), discontinuously maintained until their suppression (1863), and recorded in non-standardised fashion, are unquestionably the must plural and diversified documented source of information on Galician emigrants, including place of origin and destination, duration of journey or stay, professional activities, gender, age, status, etc. Consequently, the input of passports, alongside other sources of diversified nature (parish archives, hospital records, customs books, etc.), has turned out to be fundamental for the recent research on Galician emigration to Portugal, as well for the enlargement of the geographical coverage of the study from the coastal province of Minho to the provinces of Trás-os-Montes and Alto Douro.

Palavras chave/Keywords:

Passaportes internos; Emigração galega; Portugal; 1700-1850.

National passports; Galician emigration; Portugal; 1700-1850. 
Los estudios sobre la emigración gallega al norte de Portugal vienen experimentando desde tiempos relativamente recientes, en concreto desde la década de 1990, un impulso sin precedentes gracias al esfuerzo común de historiadores tanto portugueses (J.F. Alves, H. Rodrigues, M. Durães y E. Lagido; etc.) como gallegos (D. González Lopo, C. Fernández Cortizo). Previamente, antes de la década de 1980, son muy pocos los estudios que se interesan por la emigración gallega a Portugal; de los años 1960 datan en concreto los trabajos de A. Meijide Pardo, que dedica uno de los capítulos de su monografía sobre la emigración gallega intrapeninsular en el siglo XVIII al éxodo al reino vecino, y de A. Vieira Braga que, utilizando como fuente escrituras notariales, da noticia de la residencia y de la actividad de maestros canteros gallegos en Guimarâes en el siglo XVIII ${ }^{1}$. Pese a estos antecedentes, en los años 1970 pocos son los progresos. El interés por esta corriente emigratoria entre los historiadores demógrafos gallegos sigue siendo escaso e indirecto y, en consecuencia, restringido a unas pocas páginas de una reducida serie de monografías comarcales (Xallas, O Morrazo, Caldevergazo, etc.) que, utilizando como fuentes las actas de defunción y las actas de matrimonio parroquiales, jerarquizan ya la importancia migratoria de los destinos peninsulares ${ }^{2}$. Entre los historiadores portugueses este interés se pospone hasta la siguiente década; en unos casos, es directo y definido, en otros, tan sólo indirecto y secundario, pero en ambos casos los estudios respectivos ganan en amplitud y precisión espacial al documentar la presencia y la actividad laboral de emigrantes gallegos ya en diferentes villas y comarcas del norte de Portugal. Así, a partir de fuentes dispares, se atestigua su establecimiento en Viana do Castelo en el siglo XVI o en

1 MEIJIDE PARDO, Antonio - La emigración gallega intrapeninsular en el siglo XVIII. Madrid, 1960; VIEIRA BRAGA, Alberto - Mestres de pedraría do Reino da Galiza, assistentes en Guimarâes. Boletín de la Comisión Provincial de Monumentos Históricos y Artísticos de Orense. T. XX (1959-1960) 397-408.

2 Entre las monografías comarcales, véanse BARREIRO MALLÓN, Baudilio - La jurisdicción de Xallas en el siglo XVIII. Población, sociedad y economía. Santiago de C., 1977, p. 249-251; RODRÍGUEZ FERREIRO, Hilario - A xurisdicción do Morrazo. Séculos XVII-XVIII. Pontevedra, 2003, T. I, p. 321-343; BUGALLO VIDAL, Elisa - La antigua jurisdicción de Caldevergazo. Un Estudio Socioeconómico. Memoria de Licenciatura inédita. Santiago de Compostela, 1979, p. 201-208. 
Póvoa de Varzim también desde el Quinientos33; a partir de la información de las actas de defunción y de matrimonio, se verifica asimismo la estancia de gallegos en Guimarães en el siglo XVIII, como también en diferentes parroquias rurales de las provincias del Minho y de Tras-os-Montes4; asimismo más hacia el interior, gracias a los datos de los libros de "receitas" y "despesas" de las quintas durienses de la Congregación del Oratorio de Oporto, en la región vitícola del Alto Douro5; finalmente, también abundan los testimonios sobre la circulación de arrieros y comerciantes gallegos a través de la frontera fluvial y de la raia seca transmontana, que queda registrada en los libros de "receitas" y de "termos de fianças y guías" de las

3 MOREIRA, Manuel António Fernandes - A presença de galegos en Viana da Foz do Lima no século XVI", in Actas do Colóquio Santos Graça de Etnografía Marítima. Póvoa de Varzim, 1985, vol. IV, p. 65-93; FANGUEIRO, Óscar - A emigraçao galega para a Póvoa de Varzim do século XVI ao XVIII, in Actas do Colóquio Santos Graça de Etnografía Marítima. Póvoa de Varzim, 1985, vol. III, p. 205-229.

4 AMORIM, Maria Norberta - Guimarães, 1500-1819. Estudo demográfico. Lisboa, 1987, p. 361-378. A esta monografía le seguirá, avanzada la década de 1990, toda una serie de estudios locales, la mayor parte de ellos "dissertações de Mestrado" y tan sólo unos pocos publicados, que precisan la frecuencia de defunciones y de matrimonios de emigrantes gallegos en las respectivas parroquias. Sin pretensión de exhaustividad, pueden citarse VENTURA, Maria Manuela - S. Tiago de Mouquim. Comportamentos demográficos de uma paróquia rural Famalicense, 1609-1878. Dissertação de Mestrado, Guimarâes, 1997, p. 84; GUIMARÃES, Carlolta Maria - Santa María de Adoufe: Comportamentos Demográficos e Sociais (1780-1910). Dissertação de Mestrado, 1998, p. 113-119; FARIA, INÊS - Santo André de Barcelinhos: o difícil equilíbrio de uma população, 1606-1910. Guimarães, 1998, p. 174; FAUSTINO, José Alfredo - Calvão, uma Paróquia do Alto Tamega (1670-1870). Chaves, 1998, p. 190-191; SANTOS, Carlota - Santiago de Romarigães, comunidade rural do Alto Minho: Sociedade e Demografía (1640-1872). 1999, p. 148; MAIA, Rui Leandro São Miguel de Barreiros e a sua população, 1700-1925. Estudo demográfico. Dissertaçâo de Mestrado. Guimarães, 2000; SOLÉ, Maria Glória - Meadela, comunidade rural do Alto Minho: Sociedade e Demografía (1593-1850). Guimarães, 2001, p. 136; GONÇALVES, Maria Luísa - Comportamentos demográficos de uma comunidade minhota: o caso de Salamonde (1690-1910). Dissertação de Mestrado. Guimarães, 2002, p. 91-92; JUNCAL, Cândido Martim - Vidas a través das gerações. Comportamentos demográficos de uma comunidade rural do Baixo Minho: Santiago de Antas, 1581-1910. Dissertação de Mestrado. Guimarães, 2003; LAGIDO, Emília - Santa Maria de Ancora (1624-1910). População e Sociedade. Guimarães, 2004, p. 123-124 y 175-179; etc.

5 PEREIRA, Gaspar Martins - As quintas do Oratório de Porto no Alto Douro. Revista de História Económica e Social. 13 (1984) 13-49. 
"alfândegas" de Valença do Minho, Monção, Caminha, Chaves, Montalegre, Vinhais, etc ${ }^{6}$.

Con estos antecedentes de un lado y del otro de la frontera, en la década de 1990 este interés, hasta ahora en muchos casos indirecto y secundario, gana ya en amplitud temática, espacial y temporal; sin duda no fue ajeno a este proceso la definitiva toma de conciencia por los historiadores modernistas compostelanos de la pluralidad de los modelos migratorios gallegos, entre los cuales el de destino portugués no había merecido hasta entonces la atención que por su importancia para algunas comarcas debía tener, pero también contribuyó a este renovado impulso investigador la exploración y consulta de nuevas fuentes documentales: en territorio gallego, por ejemplo, los padrones municipales, los expedientes de quintas y la correspondencia y documentación consulares españolas ${ }^{7} \mathrm{y}$, al otro lado de la frontera, los registros de entradas de enfermos de las Casas de Misericordia y los registros de admisión de expósitos en las Rodas ${ }^{8}$, los pasaportes internos y los títulos de residencia- ${ }^{9}$. Y precisamente, la novedad de la presente década

${ }^{6}$ CAPELA, José Viriato - O comércio galaico-minhoto pela fronteira terrestre. Análise do movimento da Alfândega de Vila Nova da Cerveira de 1788 a 1833 (breve Nota). Cadernos do Noroeste. Vol. 3-nº 1-2 (1990) 65-79; FERREIRA, Maria Teresa - As Alfândegas de Trás-os-Montes: anos de 1791 e 1801. Estudos Transmontanos. 1 (1983) 196-199.

7 EIRAS ROEL, Antonio (ed.) - Aportaciones al estudio de la emigración gallega. Un enfoque comarcal. Santiago de C., 1992; LÓPEZ TABOADA, José Antonio - Emigración gallega a Portugal en la primera mitad del siglo XIX, in EIRAS ROEL, Antonio; REY CASTELAO, Ofelia (eds.) - Migraciones internas y medium distance en la Península Ibérica, 1500-1900. Santiago de Compostela, 1993, vol. II, p. 417-426.

8 COSTA, Américo Fernando - Poder e conflito. A Santa Casa da Misericórdia de Guimarães (1650-1800). Braga, 1997, p. 199-200; ARAÚJO, Maria Marta Dar aos pobres é emprestar a Deus: As Misericórdias de Vila Viçosa e Ponte de Lima (Séculos XVI-XVIII). Vila Viçosa-Ponte de Lima, 2000, p. 643-657; más recientemente de la misma autora, A Misericórdia de Monção: fronteira, guerras e caridade (1561-1810). Monção, 2008, p. 250-256. También en los fondos documentales de las Casas de Rodas del norte de Portugal aparecen noticias sobre la admisión de expósitos de madres gallegas y, asimismo, sobre la contratación de amas de leche gallegas. RODRIGUES, Henrique - Expostos no Alto Minho no Século XIX e Contextos Migratórios. Estudos Regionais. Vol. XXV (2005) 7-79; FONTE, Teodoro Afonso da - No limiar da honra e da pobreza. A infância desvalida e abandonada no Alto Minho (1698-1924). 2005, p. 494-508.

9 ALVES, Jorge Fernandes; FERREIRA, Maria Fernanda; MONTEIRO, Maria do Rosário - Imigração galega na cidade do Porto ( $2^{\mathrm{a}}$ metade do século XIX). Revista da Faculdade de Letras. Historia. Vol. IX (1992) 215-236; RODRIGUES, Henrique - Emigração galega para o Brasil através de Viana do Castelo (1838-1860). Analise a alfabetização e ao perfil socioprofissional, in EIRAS ROEL, Antonio (ed.) - Aportaciones..., cit., p. 177-183; 
ha sido la consulta más sistemática y regular de estas de fuentes, puestas al servicio, novedad igual de destacada, de la "ampliación espacial" del área de estudio que, de estar hasta este momento casi exclusivamente circunscripta a la franja litoral desde Viana do Castelo hasta Lisboa (Viana do Castelo, Póvoa de Varzim, Vila do Conde, Porto), en la actualidad cubre un territorio más extenso, que se prolonga por el interior miñoto (Barcelos, Braga, Guimarães, etc.) hasta la provincia de Trás-os-Montes y Alto Douro ${ }^{10}$. Por esta razón, en el momento presente la emigración gallega con destino al norte de Portugal ya empieza a ser mejor conocida en sus ritmos evolutivos, en sus modalidades de desplazamientos, en las procedencias comarcales y destinos de los emigrantes y, finalmente, en sus condiciones personales -sexo,

ALVES, Jorge Fernandes - Peregrinos do traballo. Perspectivas sobre a inmigración galega en Porto". Estudios Migratorios. 4 (1997) 69-81; PILOTO, Maria Adelina; SANTOS, António Fluxo migratório galego para Vila do Conde (1769-1810). População e Sociedade, 4 (1998) 285-319; FERREIRA, J., Mobilidade interna da população portuguesa: os livros de registo de passaportes do concelho de Penafiel (1770-1833). Tese de Mestrado inédita. Porto, 1997.

${ }^{10}$ GONZÁLEZ LOPO, Domingo - La emigración a Portugal desde el suroeste de Galicia en los siglos XVIII al XIX in Actas do Colóquio Internacional sobre Emigração e Imigração em Portugal (séc. XIX-XX), Lisboa, 1993, p. 373-391; con posterioridad, del mismo autor, Los movimientos migratorios en tierras del interior de la provincia de Pontevedra entre 1801-1950: características y puntos de destino. SEMATA. 11 (1999) 269-298; ibidem, Se se mandassem embora nâo haveria quem servisse... Os galegos em Portugal: un ejemplo típico de mobilidade na época pré-industrial, in LOIS GONZÁLEZ, Rubén; Camilo; VERDUGO MATÉS, Rosa María (eds.) - As migracións en Galiza e Portugal. Contributos desde as Ciencias Sociais. A Coruña, 2006, p. 237-266. DURÃES, Margarida; LAGIDO, Emília; CARIDADE, Cristina - Une population qui bouge: les migrations temporaires et saisonnières à partir de Viana do Castelo (XVIIIe-XIXe siècles). Obradoiro de Historia Moderna. 15 (2006) 29-76; LAGIDO, Emília; DURÃES, Margarida - Mobilidade interna: migrações socioprofissionais dos Alto Minhotos (séculos XVIII-XIX). Noroeste. Revista de História. vol. I (2006, 2) 74-78; DURÃES, Margarida - As mulheres estrangeiras no noroeste de Portugal: imigrações femininas galegas do ponto de vista português (sécs. XIX-XX), en HERNÁNDEZ BORGE, Julio; GONZÁLEZ LOPO, Domingo (eds.) - Mujer y emigración. Una perspectiva plural. Santiago de Compostela, 2008, p. 133-150. FERNÁNDEZ CORTIZO, Camilo - La emigración gallega a las provincias portuguesas del Miño y de Trás-os-Montes y Alto Duero durante el siglo XVIII y la primera mitad del XIX. Noroeste. Revista de História, vol. I, (2006, 2) 39-58; FERNÁNDEZ CORTIZO, Camilo - Ir aos ganhos: a emigración galega ao norte de Portugal (1700-1850), en HERNÁNDEZ BORGE, Julio; GONZÁLEZ LOPO, Domingo (coords.) - Pasado e presente do fenómeno migratorio galego en Europa. Santiago de Compostela, 2007, p. 17-49; FERNÁNDEZ CORTIZO, Camilo - La emigración gallega a la provincia portuguesa de Tras-os-Montes y Alto Douro (1700-1850): Evolución temporal, tipología y localidades de destino. Douro. Estudos \& Documentos. 22 (2007) 79-112. 
edad y estado- y ocupaciones profesionales. Y sin duda, en este proceso de profundización del conocimiento de estos diferentes aspectos de la emigración gallega a Portugal, aunque tan sólo para el periodo que transcurre desde mediados del XVIII a mediados del XIX, porque se establecen en 1760 y se extinguen en 1863, los pasaportes internos constituyen sin duda un soporte básico. Tardíos en su implantación, tampoco presentan en todos los casos una continuidad temporal prolongada; así, de los pasaportes internos autorizados en Penafiel sólo han llegado hasta nosotros los del periodo 1772-1829; de los emitidos en Viana de Castelo, se conservan los de los años 1760-1767 y, con posterioridad, los del periodo 1808-1836; de los solicitados en Chaves, los correspondientes a los años 1834 y 1835; finalmente, de los registrados en Oporto, los del año 1833, aunque en este caso se han conservado también el "registo de guias de trânsito" de los años 1847-1851 y diferentes libros de "registo de vistos em passaportes" desde el año $1847^{11}$.

\section{Pasaportes internos: implantación y reglamentación}

Los pasaportes internos portugueses, al igual que los de la monarquía hispánica, se establecen con la función de control de la movilidad interna ${ }^{12}$. Su creación acontece en tiempos del gobierno del Marqués de Pombal, en concreto por el Alvará de Declaração de 25 de Junio de 1760, que inicialmente prescribía la obligatoriedad de los pasaportes internos tan sólo para los viajeros con destino a Lisboa, pero unos meses más tarde por un nuevo

${ }^{11}$ Arquivo Municipal de Penafiel (AMP), Passaportes internos. Livros 1.988 y 1.989. Arquivo Distrital de Vila Real (ADVR), Passaportes Chaves. Lv 1.606; Biblioteca Municipal de Viana do Castelo. Registo de Passaportes, livros 1202-1207; Arquivo Distrital do Porto (ADP). Governo Civil do Porto. Registos de Pasaportes. PT/ADPRT/AC/GCPRT/J-E/026-001/3238, 3239, 3240, 3241. Registo de guías de trânsito, PT/ADPRT/AC/GCPRT/J-E/026-001/3957. Registo de vistos em passaportes, PT/ADPRT/AC/GCPRT/J-E/038-001/3663.

${ }^{12}$ El presente apartado resume las informaciones contenidas en LIMA, António - Emigração: seu regimen, passaportes. Famalicão, 1929; FERREIRA, J. - Mobilidade interna..., cit., p. 33-44; RODRIGUES, Henrique - Emigração e emigrantes do Vale do Lima no século $X I X$. Viana do Castelo, 2006, p. 23-28; DURÂES, Margarida; LAGIDO, Emília - A arte de trabalhar a pedra: migrações temporárias e sazonais no Norte de Portugal (Sécs. XVIII-XIX), in MENESES, Avelino de; COSTA, João Paulo (coords.) - O Reino, as Ilhas e o Mar Océano: Estudos em homenagem a Artur Teodoro de Matos. Lisboa, 2007, vol. 1, p. 241-245. 
Alvará de 13 de Agosto de 1760 era ampliada ya a "todas as comarcas destes Reinos" y a todos los transeúntes nacionales y extranjeros "que houverem de sahir dellas para fora". Su emisión era atribuida a las Secretarías de Estado, a la Intendencia Geral de Policía de la Corte y del Reino y, en las comarcas portuguesas, a sus corregidores o a sus respectivos "juízes de fora”, no pudiendo exceder el permiso de viaje la duración de un año. En los años siguientes, estas disposiciones no experimentan apenas cambios, con la salvedad que durante las invasiones francesas (1807-1811), con el fin de reforzar el control de la movilidad interna, sucesivos "editaes" (1808, 1809, 1810 y 1811) del Intendente Geral de Policía insisten en la obligatoriedad de los pasaportes internos. Así, el edital de 20 de Mayo de 1808 ordenaba que "nehua Pessoa de qualquer qualidade que seja possa viajar ou sahir fora desta comarca sem o passaporte asignado pelo corregedor ou juises de fora (...); e cazo não traga ou apresente passaporte será prezo"; de nuevo, el "edital" de 19 de Febrero de 1811 se pronuncia en los mismos términos a cerca de su obligatoriedad, dispensando, entre otros exceptuados, a las "pessoas que nas Comarcas destes Reinos fizerem jornadas para lugares que fiquem dentro nellas, sendo regularmente pessoas conhecidas".

Esta reglamentación sólo experimentará cambios sustanciales con posterioridad a la revolución liberal; en concreto la Ley de 25 de Mayo de 1825 contenía diferentes disposiciones para regularizar la concesión de pasaportes, evitar su falsificación y fiscalizar más estrictamente a los viajeros nacionales y extranjeros; además establecía su obligatoriedad para los que se desplazasen más allá de 5 leguas de su residencia, al tiempo que centralizaba el sistema de vigilancia y de control de la movilidad de la población en la recién creada Secretaría-Geral de Passaportes. Años más tarde, aunque en el intermedio D. Miguel había abolido en 1828 la anterior ley, una nueva, de fecha 18 de julio de 1835, que implanta la nueva división y organización administrativa del Reino, introducía nuevas reformas, al establecer en adelante cuatro modelos de impresos y asignar la emisión de los pasaportes en las comarcas a los sub-prefectos, y de los pasaportes de salida de un municipio para otro o para la frontera a los administradores de los concejos.

La vigencia de los pasaportes internos va a prorrogarse hasta 1863, en que la Ley de 31 de Enero en su Artículo 2 dispone que todos los nacionales y extranjeros "podem viajar e transitar libremente", procediendo 
en consecuencia a su abolición; pocos meses después, la carta de Ley de 7 de Abril de 1863 ratificaba la libertad de tránsito en territorio portugués.

Durante estos más de cien años de vigencia, entre 1760 y 1863 , y debido a su finalidad de fiscalización y control de la movilidad interna, los pasaportes internos constituyen, por razón de su información plural y heterogénea, una fuente inexcusable para el estudio de la emigración gallega al norte de Portugal de la segunda mitad del siglo XVIII y de la primera mitad del XIX. Las distintas disposiciones legales prescribían a las autoridades emisoras la información y registro de toda una serie de datos relativos a la descripción física y a las condiciones personales y profesional del transeúnte, como también otros referidos a la fecha de emisión del pasaporte, tiempo de duración, destino, etc. Por lo tanto, la información que proporcionan sobre los transeúntes gallegos es plural y variada. En concreto, nominan a los titulares, aunque en muy pocos casos explicitan su parroquia de origen, limitándose a identificarlos como gallegos; registran el día de solicitud y el tiempo de duración del permiso de viaje, como también el destino y en ocasiones el itinerario; consignan los datos relativos al sexo y, ya de forma más irregular, los referidos al estado, a la edad y a la profesión de los transeúntes; finalmente, proporcionan una descripción de las "signaes" personales (altura, rostro, cabello, etc.) y, en algunos casos, también solicitan la firma de los portadores. Con tal riqueza de información, los pasaportes internos se han convertido en fechas muy recientes en una pieza fundamental, aunque complementaria, para la investigación sobre la emigración gallega al norte de Portugal en general, pero asimismo para un trabajo como el presente, que se plantea como objetivo, a partir de su consulta en complementariedad con la de otros fondos documentales, el análisis de las condiciones personales - sexo, estado y edad - y de las dedicaciones profesionales de los emigrantes gallegos, aunque, como ya está anticipado, los pasaportes internos ofrecen una información más amplia - localidades de origen y de destino, duración de la estancia, etc.-, que ahora no se toma en consideración por haber sido ya objeto de atención en anteriores trabajos de investigación ${ }^{13}$.

${ }^{13}$ FERNÁNDEZ CORTIZO, Camilo - Ir aos ganhos: a emigración galega..., cit., p. 17-49; FERNÁNDEZ CORTIZO, Camilo - La emigración gallega..., cit., p. 79-112. 


\section{Condiciones personales de los emigrantes gallegos: sexo, edad y estado}

El éxodo a Portugal es un fenómeno ciertamente masculino, pero en las fuentes documentales que analizamos, por comparación con otras como las actas de honras fúnebres parroquiales o los registros de entrada de enfermos de los hospitales de las Casas de Misericordia portuguesas ${ }^{14}$, esta hegemonía de los varones se refuerza todavía más. En los pasaportes internos expedidos en Chaves (1834-1835) no figura ninguna mujer, pero sí, aunque en muy modesto número, en los de Penafiel como acompañante de su marido (6,6\%). En el litoral, la proporción de mujeres transeúntes prosiguen siendo modesta: en Viana do Castelo, las portadoras de pasaporte suponen en periodo 1809-1836 el 1,7\%, cifra que se incrementa al 3,6\% si agregamos a los acompañantes; en cambio, ninguna mujer figura como titular en los pasaportes de Vila do Conde (1769-1810), como tampoco en el "registo de vistos em passaportes" de Oporto (1847-1849), aunque sí como acompañantes de su marido $(0,4 \%)^{15}$.

También el estado de los emigrantes gallegos a Portugal presenta un acusado contraste según se consideren los registros de enfermos de los hospitales de las Misericordias o los registros de pasaportes internos. En la primera fuente, la superioridad estadística corresponde a los solteros tanto de un sexo como de otro; en consecuencia, en los centros hospitalarios de la provincia transmontana la proporción de enfermos casados era por regla

${ }^{14}$ En el municipio de La Cañiza tan sólo el 2,7\% de los vecinos ausentes fallecidos en Portugal durante el siglo XVIII y la primera mitad del XIX son mujeres. REY CASTELAO, Ofelia; PÉREZ RODRÍGUEZ, Francisco - Movimientos migratorios en el municipio de A Cañiza, siglos XVII al XIX, in EIRAS ROEL, Antonio (ed.) - Aportaciones al estudio..., cit., p. 40. Sobre el total de enfermos gallegos ingresados en los hospitales de las Casas de Misericórdia de Mesâo Frio, de Vila Real y de Amarante la proporción de mujeres oscilaba en las postrimerías del siglo XVIII y en la primera mitad del siglo XIX entre el 2 y el 6,5\%; en cambio, en los hospitales de localidades fronterizas estos porcentajes se incrementaban fuertemente: en Chaves, hasta el 18,4\%; en Caminha y en Viana do Castelo respectivamente hasta el $47,1 \%$ y $35,7 \%$.

${ }^{15}$ LAGIDO, Emília; DURãES, Margarida - Mobilidade interna..., cit., p. 76; PILOTO, Maria Adelina; SANTOS, António - Fluxo..., cit., p. 297. 
general modesta: entre el 5 y el 10\% en Vila Real (1797-1846); del 14,9\% en Chaves (1827-1837) y, finalmente, en Amarante (1835-1839), del 27,3\%. Por el contrario, entre los titulares de los pasaportes internos de Chaves y de Viana do Castelo, de las décadas de 1820 y 1830, son ya más numerosos los casados; sumados a los viudos y distribuidos proporcionalmente los indeterminados, los transeúntes de estado casado oscilarían entre 53-55\%, mientras que los solteros lo harían entre el $35-40 \%{ }^{16}$. También en el "registo de vistos em passaportes" levantado por las autoridades de Oporto, cuyo uso se ha preferido al "registo de passaportes internos" a causa de su dudosa representatividad (14 viajeros gallegos), los casados, que casi suman el 50\%, mantienen su predominio numérico.

Tabla 1 - Estado de los emigrantes gallegos

\begin{tabular}{|c|c|c|c|}
\hline & Chaves & Viana do Castelo & Oporto \\
\cline { 2 - 4 } & $1834-1835$ & $1823-1831$ & $1847-1848$ \\
\hline Soltero & 37,1 & 33,5 & 41,8 \\
\hline Casado & 48,6 & 41,8 & 46,6 \\
\hline Viudo & 1,4 & 2,7 & 2,2 \\
\hline Indeterminado & 12,9 & 20,2 & 9,0 \\
\hline Soltera & 0,0 & 0,4 & 0,2 \\
\hline Casada & 0,0 & 1,5 & 0,0 \\
\hline Viuda & 0,0 & 0,0 & 0,2 \\
\hline Indeterminada & 0,0 & 0,0 & 0,0 \\
\hline Casos & 70 & 263 & 455 \\
\hline
\end{tabular}

FUENTES: Arquivo Distrital de Vila Real, Passaportes Chaves. Lv 1.606. Biblioteca Municipal de Viana do Castelo, Registo de Passaportes, livros 1205-1207. Arquivo Distrital do Porto, Registo de vistos em passaportes, PT/ADPRT/AC/GCPRT/J; E/038- 001/3663.

${ }^{16}$ Los pasaportes de Vila do Conde (1769-1863) otorgan, por el contrario, la hegemonía a los solteros (40\%) frente a los casados (30\%). PILOTO, Maria Adelina; SANTOS, António Fluxo..., cit., p. 297. En la ciudad de Oporto, los títulos de residencia anuales son concedidos por las autoridades policiales en 1888 mayoritariamente a solteros $(62,4 \%)$ y solteras $(91,5 \%)$ por comparación con casados y viudos hombres $(37,6 \%)$ y mujeres $(8,5 \%)$; en cambio, los títulos de residencia permanente invierten la correlación, con el consiguiente predominio de los casados y viudos $(77,6 \%)$ frente a los solteros (20,2\%); el matrimonio era, por lo tanto, uno de los factores más condicionante de la permanencia definitiva. ALVES, Jorge Fernandes; FERREIRA, Maria Fernanda; MONTEIRO, Maria do Rosário - Imigraçâo galega..., cit., p. 229; ALVES, Jorge Fernandes - Peregrinos..., cit., p. 74. 
Finalmente, también en cuanto a la estructura de edad en los pasaportes internos de transeúntes gallegos y los registros hospitalarios de enfermos gallegos persisten las discrepancias, aunque en el presente caso la representatividad de la muestra no autoriza conclusiones seguras. La edad media de los gallegos ingresados en la Casa de Misericordia de Barcelos (1848-1850) ascendía en concreto a 25,2 años; un poco superior -26,75 añosera la de los gallegos asistidos en el hospital de Amarante en la década de 1830. Los registros de pasaportes elevan, en cambio, estos promedios por encima de los 30 años.

Tabla 2 - Edad de los gallegos con pasaporte interno

\begin{tabular}{|c|c|c|c|c|}
\hline \multirow{2}{*}{ Edad } & Penafiel & Chaves & Viana do Castelo & Oporto \\
\cline { 2 - 5 } & $1772-1829$ & $1834-1835$ & $1823-1831$ & 1833 \\
\hline$<20$ & 9,1 & 0,0 & 11,0 & 9,1 \\
\hline $20-24$ & 16,7 & 28,6 & 18,1 & 18,2 \\
\hline $25-29$ & 12,1 & 20,0 & 14,8 & 9,1 \\
\hline $30-34$ & 13,6 & 20,0 & 18,7 & 36,4 \\
\hline $35-39$ & 12,1 & 15,7 & 15,9 & 9,1 \\
\hline $40-44$ & 7,6 & 11,4 & 7,1 & 0,0 \\
\hline $45-49$ & 13,6 & 0,0 & 3,8 & 9,1 \\
\hline $50-54$ & 4,5 & 1,4 & 4,4 & 0,0 \\
\hline $55-59$ & 4,5 & 0,0 & 4,9 & 0,0 \\
\hline 60 y + & 6,0 & 2,8 & 1,1 & 9,1 \\
\hline Indeterminado & 0,0 & 0,0 & 0,0 & 0,0 \\
\hline Casos & 66 & 70 & 182 & 11 \\
\hline Edad media & 35,6 años & 30,3 años & 32,1 años & 32,1 años \\
\hline
\end{tabular}

FUENTES: Arquivo Municipal de Penafiel, Passaportes internos. Livros 1.988 y 1.989. Arquivo Distrital de Vila Real, Passaportes Chaves. Lv 1.606. Biblioteca Municipal de Viana do Castelo, Registo de Pasaportes, livros 1205-1207. Arquivo Distrital do Porto, Governo Civil do Porto. Registos de Pasaportes. PT/ADPRT/AC/GCPRT/ /J-E/026-001/3238, 3239, 3240, 3241.

Los titulares de permisos de viaje con edad inferior a los 25 años oscilan en los pasaportes de Penafiel, de Chaves, de Viana do Castelo y de Oporto entre el $25 \%$ y el $29 \%$; los que no han cumplido los 30 años, a su vez, entre el $36 \%$ y el $49 \%$, cuando en el caso de los gallegos enfermos se aproximaba a los dos tercios. A su vez, los de los grupos de edad 30-49 años componen todavía un importante contingente migratorio, entre el $45 \%$ y el $50 \%$; los de más edad, que no comparecen en los registros hospitalarios, 
suponen un modesto número, pero, aún así, alcanzan entre el 9-15\% de los solicitantes de pasaportes. En consecuencia, la edad media alcanza entre éstos valores superiores, que superan siempre los 30 años e incluso entre los transeúntes por Penafiel los 35 años ${ }^{17}$.

En definitiva, la emigración portuguesa enrola mayoritariamente a población masculina, de condición tanto soltera como casada, cuya edad en general es joven, ya que predominan los emigrantes con edades comprendidas entre los 15 y 39 años, de forma que los registros hospitalarios cifran la edad media en 25-27 años que, en cambio, elevan los pasaportes internos a 30-35 años.

\section{Las actividades profesionales de los emigrantes gallegos a Portugal}

Los pasaportes internos se vienen postulando como una fuente documental inexcusable en el análisis de aspectos relevantes de la emigración gallega a Portugal, tal como se ha demostrado en apartado de las condiciones personales -sexo, estado y edad- de los emigrantes, pero su concurso también es fundamental a la hora de precisar los principales actividades laborales ejercidas en tierras portuguesas.

La emigración gallega a la provincia a la región de Entre-Douro-e-Minho, dejando al margen exiliados, refugiados políticos y facciosos fronterizos, es por supuesto de naturaleza laboral y su objetivo, por consiguiente,

${ }^{17}$ Los emigrantes gallegos, la mayor parte de ellos residentes previamente en territorio portugués, que obtienen pasaporte para Brasil en Viana do Castelo (1838-1860) contaban en el $62,7 \%$ de los casos con menos de 30 años; su edad media era, en concreto, de 26 años. RODRIGUES, Henrique - Emigração galega..., cit., p. 182-183. En Vila do Conde, los titulares de pasaportes internos en su mayoría tenían también menos de 30 años, sumando aproximadamente el 60\%; a partir de los 45 años el decrecimiento de la movilidad era ya acusada. PILOTO, Maria Adelina; SANTOS, António - Fluxo..., cit., p. 296. Finalmente, los titulares de los permisos de residencia anual en la ciudad de Oporto con edades inferiores a los 25 años acumulaban en 1888 el 37,9\% del total; los menores de 30 años sobrepasaban ya la mitad (52,4\%). A continuación, los residentes con edades comprendidas entre 30 y 49 años suponían el 36,9\% y los de edades superiores, el 10\%. Entre los titulares de permisos de residencia permanente, los grupos de edad anteriores a 35 años no constaban, siendo los mayores de 50 años los más numerosos a la hora de su solicitud (76,9\%). ALVES, Jorge Fernandes; FERREIRA, Maria Fernanda; MONTEIRO, Maria do Rosário - Imigração galega..., cit., p. 228-229. 
es "ganar a súa vida" debido a las oportunidades de empleo y salarios más ventajosos que ofrecen la provincia miñota y la transmontana a partir de los años 1720. Por sectores económicos, los fondos de los pasaportes internos y de los títulos de residencia anuales (Oporto) permiten sintetizar el siguiente cuadro profesional:

Tabla 3 - Sectores de actividades económicas de los emigrantes gallegos

\begin{tabular}{|c|c|c|c|c|c|}
\hline & Penafiel & Viana & Chaves & Vila do Conde & Oporto \\
\cline { 2 - 6 } & $1772-1829$ & $1823-1831$ & $1834-1835$ & $1769-1863$ & 1888 \\
\hline Primario & 2,7 & 16,9 & 4,3 & 5,6 & 0,9 \\
\hline Secundario & 52,6 & 7,5 & 4,2 & 11,9 & 8,9 \\
\hline Terciario & 12,9 & 72,4 & 87,2 & 72,5 & 90,2 \\
\hline Pobres & 7,3 & 0,3 & 0,0 & 0,0 & 0,0 \\
\hline Indeterminado & 24,5 & 3,0 & 4,3 & 10,0 & 0,0 \\
\hline Casos & 122 & 609 & 70 & 160 & 2.391 \\
\hline
\end{tabular}

FUENTES: Arquivo Distrital de Vila Real, Passaportes Chaves. Lv 1.606. Arquivo Municipal de Penafiel. Passaportes internos. Livros 1.988 y 1.989. Biblioteca Municipal de Viana do Castelo, Registo de Pasaportes, livros 1205-1207. PILOTO, Maria Adelina; SANTOS, António - Fluxo..., cit., p. 299. ALVES, Jorge Fernandes; FERREIRA, Maria Fernanda; MONTEIRO, Maria do Rosário - Imigração galega..., cit., p. 231.

Los pasaportes internos y también los títulos de residencia anuales concedidos en Oporto privilegian el ramo terciario frente a los otros dos sectores, con excepción de Penafiel, donde los transeúntes ejercen en su mayoría actividades secundarias, preferentemente como canteros y secundariamente como coheteros, en este caso en complementariedad con otros oficios (cerero, tamborilero). También en Viana do Castelo, en Vila do Conde y, finalmente, en Oporto la cantería es el oficio más frecuente entre los emigrantes con actividad secundaria; pero como ya se ha señalado, el sector con mayor difusión es el terciario, aunque con diferencias de unos núcleos a otros. En Viana do Castelo, donde la mayoría de los solicitantes de pasaportes se dirigen a Lisboa, y en Oporto, los trabajadores y los criados de servir reúnen respectivamente el 57,7\% y 75,4\% de los emigrantes registrados; en los pasaportes internos de Chaves y de Penafiel, los trabajadores, en cambio, tienen una presencia muy modesta y algo más elevada los criados y asistentes que alcanzan respectivamente el 1,4\% y el $10,2 \%$. Por el contrario, entre los solicitantes de permisos de viaje en la primera de estas villas, la dedicación comercial es la dominante hasta el punto 
de concentrar el 85,8\% del total. En cambio, el sector primario tiene escaso peso económico entre los que pasan por Chaves $(1,4 \%)$ y por Penafiel $(2,7 \%)$, pero ya superior entre los que transitan por Viana do Castelo $(16,9 \%)^{18}$.

Tabla 4 - Actividad profesional de los gallegos con pasaporte

\begin{tabular}{|c|c|c|c|c|c|}
\hline \multicolumn{2}{|c|}{ Chaves } & \multicolumn{2}{|c|}{ Penafiel } & \multicolumn{2}{|c|}{ Viana do Castelo } \\
\hline \multicolumn{2}{|c|}{ 1834-1835 } & \multicolumn{2}{|c|}{$1772-1829$} & \multicolumn{2}{|c|}{$1823-1831$} \\
\hline Labrador & 1,4 & Labrador & 2,7 & Labrador & 12,3 \\
\hline Criado servir & 1,4 & Criado servir & 4,5 & Jornalero & 4,6 \\
\hline Trabajador & 2,9 & Asistente & 5,5 & Trabajador & 43,7 \\
\hline Calderero & 1,4 & Cajero & 0,9 & Criado servir & 14,0 \\
\hline Carpintero & 1,4 & Sastre & 4,5 & Marinero & 1,5 \\
\hline Serrador & 1,4 & Cerero & 1,8 & Sastre & 0,7 \\
\hline Negociante & 2,9 & Cantero & 34,5 & Cantero & 2,6 \\
\hline Traficante & 1,4 & Cohetero & 1,8 & Carpintero & 0,8 \\
\hline Tendero & 12,9 & Tamborilero & 0,9 & Fabricante peines & 0,7 \\
\hline Vendilhao & 58,6 & $\begin{array}{l}\text { Cerero/cohetero/ } \\
\text { tamborilero }\end{array}$ & 9,0 & Tejero & 1,5 \\
\hline Transitar Reino & 10,0 & Negociante & 0,9 & Otros Secundarios & 1,2 \\
\hline Indeterminado & 4,3 & Músico & 0,9 & Aguador & 1,5 \\
\hline & & Mendigo & 7,3 & Arriero & 1,1 \\
\hline & & Indeterminado & 24,6 & Negociante & 2,6 \\
\hline & & & & Comerciante & 0,8 \\
\hline & & & & Tendero & 1,3 \\
\hline & & & & Quincallero & 0,8 \\
\hline & & & & Sardinero & 0,3 \\
\hline & & & & Mendigo & 0,3 \\
\hline & & & & Otros Terciarios & 4,8 \\
\hline & & & & Indeterminado & 3,0 \\
\hline
\end{tabular}

FUENTES: Arquivo Municipal de Penafiel, Passaportes internos. Livros 1.988 y 1.989. Arquivo Distrital de Vila Real, Passaportes Chaves. Lv 1.606. Biblioteca Municipal de Viana do Castelo, Registo de Pasaportes, livros 1205-1207.

De forma ya más pormenorizada, las principales ocupaciones laborales ejercidas por los gallegos en Portugal, según los datos de la tabla 4, pueden ser reducidas a cuatro. En primer lugar, se emplean en el servicio doméstico urbano, como asistentes o criados de servir; en segundo lugar, en la actividad

${ }^{18}$ En cambio, entre los emigrantes gallegos que, en el periodo 1838-1860, obtienen pasaporte en Viana de Castelo para trasladarse a Brasil predominan los dedicados al sector primario (35,8\%), en particular jornaleros; a su vez, en el sector secundario estaban empleados el 18,9\%, destacando los canteros; finalmente, el sector terciario reunía al $24,5 \%$ de los emigrantes, entre los cuales predominaban criados y sirvientes. RODRIGUES, Henrique Emigração galega..., cit., p. 180-181 y 183. 
agrícola como "criados de lavoura" y como jornaleros; en tercer lugar, en la cantería y, finalmente, en el transporte de mercancías y en el comercio terrestre. A mayores abría que añadir a estas actividades en los núcleos costeros - Caminha, Viana do Castelo, Esposende, Póvoa de Varzim, etc. -, las de la pesca y del comercio marítimo. Es sin duda en estos puertos del norte, como también en Lisboa, en donde se establecen las primeras colonias de pescadores y comerciantes gallegos que, sobre todo desde la segunda mitad del siglo $\mathrm{XV}$, abastecen al mercado portugués de pescado salado y fresco e importan sal. Con estos contactos comerciales previos, que se refuerzan en el siglo XVI, nada tiene de particular la persistencia de la actividad pesquera gallega tiempos después, en el siglo XVIII y, en particular, que en esta centuria los puertos gallegos y Viana sigan manteniendo un activo comercio al menos hasta la década de 1770. Al puerto vianense transportaban los negociantes gallegos pescado salado, hierro vizcaíno y otros productos, pero también participaban, en solitario o en sociedad con comerciantes vianenses, en los negocios de una plaza que protagonizaba un activo y diversificado comercio de exportación y reexportación por razón de sus tráficos con el NW. de Europa y con Brasil. En este marco de un comercio diversificado e internacional, el comercio con Galicia era protagonizado por un amplio número de pequeños y medianos comerciantes e de propietarios de lanchas en su mayor parte portugueses, pero también por algunos gallegos residentes en la ciudad ${ }^{19}$. Así, los pasaportes internos de los años 1764-1766 documentan la presencia temporal de al menos seis comerciantes naturales de Baiona. Años después, entre 1823 y 1830, al menos cuatro negociantes, entre los veintidós transeúntes portadores de pasaporte con destino mayoritariamente a Oporto $(54,6 \%)$ y Caminha $(18,2 \%)$, eran residentes en la villa portuaria, a diferencia de otros cuya estancia era temporal en esta plaza.

Ahora bien, entre estas dos fechas, entre la década de 1760 y la de 1820, esta presencia gallega se vio reducida desde la década de 1770; las causas fueron en primer lugar la guerra del pescado de 1773-1774 que

${ }^{19}$ CAPELA, José Viriato - O porto de Viana no contexto do comércio externo portugués (Análise à balança comercial de 1783) in Viana - O Mar e o Porto. Viana do Castelo, 1987, p. 94-95. 
en la práctica cierra el mercado portugués al pescado salado gallego y, en segundo lugar, los obstáculos a la intermediación gallega en el transporte de hierro vizcaíno y de paños (1778). Según los "livros de visita de saúde" de los años 1749-1773 del total de barcos inspeccionados el 34,3\% eran de procedencia gallega; en consecuencia la media anual de barcos gallegos que fondeaban en la "foz" del Lima era casi de $12^{20}$. Ahora bien, tras los años centrales de la década de 1770 por las circunstancias anteriormente citadas se produce el abandono temporal del puerto vianense por un buen número de comerciantes gallegos, pero en todo caso esta drástica reducción de los tráficos comerciales con Galicia favoreció en la última fase del siglo XVIII la reactivación del comercio interior y por la raia seca con el valle del Miño, de radio corto y también en gran medida de contrabando (sal), realizado desde Caminha y, en menor medida, desde otros núcleos fronterizos (Vilanova da Cerveira, Valença, Monção) ${ }^{21}$. Durante el último tercio del siglo XVIII la presencia de comerciantes gallegos se refuerza en estas plazas al menos hasta los años 1808-1819 en que empiezan a retornar a Viana, contribuyendo en la fase siguiente, entre 1820-1836, a su reactivación comercial. En este periodo, los pasaportes internos registran la solicitud de circulación de 36 comerciantes gallegos, aunque ciertamente la mayoría se limitan a pasar por la villa portuaria principalmente en dirección a Oporto.

La actividad pesquera experimenta también por estos años una expansión; a ella no fue ajena la instalación en el siglo XIX de colonias de pescadores, principalmente de A Guarda, en diferentes puntos de la costa desde Caminha a Viana do Castelo. Es el caso del pequeño puerto de Gontinhães, en el cual, según Baldaque da Silva, "antigamente havia aquí três ou quatro barcos de pesca pertenecentes a lavradores", pero "depois uma pequena colónia de pescadores gallegos do porto da Guardia veio estabelecerse-se néste ponto (...) e desenvolvendo-se pouco a pouco, chegou a constituir um centro de pescarias de alguna importancia"22. También en Viana do Castelo a

${ }^{20}$ BRAGA, Custódio Capela - Para a história de Viana do Castelo. Visitas de saúde aos barcos acostados no Cabedelo da Foz do Lima. Cadernos Vianenses. T. IX (1985) 114 y ss.

${ }^{21}$ CAPELA, José Viriato - O porto de Viana..., cit., p. 96-97; CAPELA, José Viriato O comércio galaico-minhoto..., cit., p. 66-67.

${ }^{22}$ SILVA, A.A. Baldaque da - Estado Actual das Pescas em Portugal. Lisboa: Imprenta Nacional, 1891, p. 83-84. CRUZ, Maria Alfreda - Caminha: Evoluçao y estrutura da vila da Foz do Minho". Caminiana. 15 (1988) 102-103. 
comienzos de la década de 1830 se establece en un barrio del puerto una colonia de refugiados gallegos, compuesta por "marítimos" y pescadores ${ }^{23}$. En un reciente estudio sobre la emigración gallega a los puertos de Vila Praia de Âncora y de Viana de Castelo, M. A. Botão Pereira do Rego cifra en tres los matrimonios con un contrayente al menos gallego celebrados anualmente en esta última ciudad en el siglo XVIII; en el primer tercio del siglo XIX, la media se rebaja a dos enlaces. Entre estos novios la mayor parte son precisamente pescadores (62\%) y, en segundo lugar, "marítimos" $(26 \%)^{24}$.

Desde Viana do Castelo y otros puertos del norte, la red comercial penetraba hacia el interior a través de los cursos de los ríos Miño y Limia, pero también por los caminos terrestres que tenían como principal nudo de comunicación la ciudad de Braga. Por el río Miño el comercio avanzaba desde Caminha hasta Valença y Monção; por el río Limia, desde Ponte de Lima hasta Ponte da Barca; a estas localidades ribereñas acudían comerciantes gallegos para abastecerse de sal y pescado salado. Su presencia está también documentada en Braga, ciudad que, por su situación estratégica, se convierte en el principal eje comercial y nudo de comunicaciones entre la costa y las tierras interiores miñotas y transmontanas. Se justifica así el interés de negociantes y comerciantes gallegos para establecerse en la ciudad bracarense porque era uno de los principales centros de distribución de la región de Entre Douro-e-Minho y no conviene olvidar que en el siglo XVIII el $80 \%$ de las exportaciones gallegas se destinaban a esta región ${ }^{25}$. Siendo el pescado salado y el fresco el principal producto de estas exportaciones nada tiene de particular que los comerciantes gallegos se interesen por establecerse en Braga e intervenir en su distribución hacia las tierras interiores, donde era comercializado en las relativamente numerosas ferias y mercados, algunas

\footnotetext{
${ }^{23}$ ABREU, Alberto Antunes de - A pesca e os pescadores de Viana do Castelo da Idade Média até meados do século XX, in Viana ..., cit., p. 22.

${ }^{24}$ REGO, Maria Aurora - Os portos de pesca de Vila Praia de Âncora e de Viana do Castelo no contexto das migrações galegas. Alguns comportamentos Demográficos in Actas do V Ciclo de Conferencias da Cátedra Unesco 226 sobre Migracións da Universidade de Santiago de Compostela. Santiago de Compostela, 2009 (en prensa).

${ }^{25}$ MEIJIDE PARDO, Antonio - "Aspectos del comercio gallego de exportación a Portugal en el siglo XVIII", en Actas I.J.M.A.C.H. Santiago de Compostela, 1975, T. III, p. 806; OLIVEIRA, Aurélio de, GARCÍA LOMBARDERO, Jaime - Alguns dados em torno das relações económicas entre o Porto - sua região e a Galiza na época moderna - séc. XVII, XVIII. Revista de História. 2 (1979) 125.
} 
de ellas muy próximas a la raia seca, como las de Chaves o de Montalegre, a las que acudían los comerciantes gallegos para aprovisionarse de sal y de pescado salado. De su actividad, así como de la de arrieros gallegos, dan noticia los pasaportes internos emitidos en Chaves en los años 1834 y 1835; asimismo de sus tráficos y del transporte de productos y de mercancías (aceite, vino, sal, almendras, lana, paños, etc.) los libros de "receitas" y de "termos de fianças y de guías" de las "alfândegas" fronterizas de Chaves, de Montalegre y de Vinhais.

"Vendilhões" (66,7\%) y, en menor número, tenderos $(28,3 \%)$ y negociantes $(5,0 \%)$ componen el sector profesional más numeroso de los titulares de los pasaportes internos expedidos en Chaves, hasta el punto de sumar el $85,8 \%$ de los portadores de estos permisos de tránsito. En su mayoría estos profesionales son de edad inferior a los 34 años; en concreto, los menores de 35 años suponen el 71,6\% del total y el grupo comprendido entre los 20-29 años, el 53,3\%; en consecuencia, la media resultante es de 29,9 años, inferior a la del sector mercantil que solicita pasaportes en Viana do Castelo (36,9 años), debido a que en esta última plaza los menores de 35 años suponen sólo el 40\% y el grupo de edad de 35-39 años concentra un porcentaje superior $(26,7 \%)^{26}$. Entre ellos, los casados son más numerosos $(51,7 \%)$ que los solteros $(33,3 \%)$. Su actividad se prolonga durante varios meses en territorio portugués, de forma que a todos ellos les son concedidos plazos de tiempo igual o superior a tres meses; los de esta duración suponen el $65 \%$ y los concedidos para estancias de seis o más meses, a su vez, el 28,4\%. Durante este tiempo los "vendilhões" y tenderos gallegos se desplazan por territorio portugués con sus productos; en concreto, al 3,3\% se le concede el permiso para transitar respectivamente por la provincia de Trás-os-Montes y por la de Minho; para dirigirse hacia el interior son autorizados, a su vez, el 50\% y, finalmente, para transitar por el Reino, el 23,3\%.

Entre estos emigrantes, por razón de sus localidades de procedencia, en particular de los municipios ourensanos de Xunqueira de Espadañado y Maceda, se incluyen también sogueros y cordeleros y vendedores de objetos y productos de cerámica, que se adentran incluso más hacia el sur, hasta las

${ }^{26}$ La muestra de pasaportes emitidos en Chaves (1834-1835) asciende a 60 casos, mientras que de los emitidos en Viana do Castelo (1825-1836), tan sólo a 17. 
provincias de Beira y del Alentejo durante varios meses. De mucha menor duración es ya la actividad de otros gallegos que, según algunos informes oficiales, entran por estas fronteras diariamente a su comercio y casi todos se recojen en el mismo día ${ }^{27}$. La naturaleza y el volumen de su actividad queda consignada en los libros de contabilidad de las "alfândegas" de Chaves, Montalegre y Vinhais. En la primera de ellas, durante los meses de junio y de julio de 1767 , se consignan un total de 183 partidas de viajes, de las cuales 115 corresponden a arrieros y traficantes gallegos (70,6\%). Del valor total del ganado y de otras mercancías que atraviesan la frontera en una y otra dirección, el 68,3\% se les asigna a ellos; sobresale el pescado (bacalao, pulpo y, sobre todo, sardina) que supone el 52,5\%; a continuación, el ganado que suma el 29,8\% del valor total y el aceite, a su vez, el 16,9\%; la sal, el sumagre y las telas son otros productos ya muy minoritarios ${ }^{28}$. En cambio, en el puerto seco de Valpaços, dependiente de la "alfândega" de Chaves, la principal actividad, según el libro "termos de fianças e guias" de año 1787, es el transporte de aceite; en concreto, del total de registros de viajes asentados el 12,3\% es realizado por arrieros gallegos, que transportan el 25,6\% de la carga ${ }^{29}$. Finalmente, en la "alfândega" de Montalegre, durante el segundo semestre de 1836, los arrieros gallegos realizan 52 viajes, transportando en este caso 599 almudes de vino que van a buscar "a la Ribeira para ver de despachar"; a su vez, durante el mismo periodo, 12 comerciantes cruzan la raia seca para transitar "polo reino adentro a su negocio" durante un plazo de tiempo que oscila entre los 8 y los 15 días $^{30}$. En definitiva, el comercio y la arriería en tierras del norte de Portugal ocupa a un importante número de naturales de Galicia hasta el punto que de los 420 arrieros censados en la provincia transmontana en 1796 la mayor parte eran gallegos.

${ }^{27}$ Archivo General de la Administración. Servicio Exterior. Consulado General de España en Lisboa, caja 54/6.491 (17/11/1826).

${ }^{28}$ Arquivo Nacional da Torre de Tombo. Erário Régio. Contas da Alfândega de Chaves, livro 20, ff. 112-137.

${ }^{29}$ Arquivo Nacional da Torre de Tombo. Erário Régio. Contas da Alfândega de Chaves. Termos de fianças e guias de Valpaços, livro 77, ff. 1-150.

${ }^{30}$ Arquivo Nacional da Torre de Tombo. Erário Régio. Contas da Alfândega de Montalegre, livro 39. 
El comercio marítimo y terrestre y el transporte eran sin duda un sector privilegiado de la presencia de gallegos en el norte de Portugal, pero ciertamente sus ocupaciones profesionales eran más diversas. Así un importante número se empleaba en el servicio doméstico como criado de servir o como sirviente o asistente. En los pasaportes de Penafiel, suman el 10\% de los portadores de pases de tránsito; en los emitidos en Viana do Castelo y en Oporto, la mayoría de ellos con destino Lisboa, esta proporción se eleva respectivamente al $14,0 \%$ y al $63,6 \%$. En el puerto vianense, son precisamente los criados los que reciben con mayor frecuencia asistencia en el hospital de la Casa de Misericórdia y, finalmente, son también ellos los que presentan una tasa de residencia más elevada, fenómeno lógico en razón de la naturaleza de su oficio. En cuanto a su edad, los de esta ocupación que transitan por Viana do Castelo son en general jóvenes; su edad media es de 29,9 años. Del total de 87 casos analizados, el 60,9\% no ha cumplido los 30 años y el 77\%, los 35 años; a su vez, los que cuentan con 50-59 años suponen el $5,7 \%$. Solteros $(45,2 \%)$ y casados $(44,1 \%)$, en ligera mayoría si le agregamos los viudos $(3,2 \%)$, se reparten casi equitativamente sus efectivos.

La condición de criados de servir en las villas de Viana do Castelo, de Chaves, de Vila Real y, sobre todo, de Oporto y de Lisboa identifica laboralmente a un importante número de emigrantes gallegos al norte de Portugal. En las zonas rurales son empleados también como asistentes y "criado de lavoura" por un plazo más o menos amplio o simplemente como jornaleros con ocasión de las distintas labores agrícolas, en particular en los viñedos y en los olivares de la región del Alto Douro. En un buen número de casos, según testimonian las actas de matrimonio y de defunción de distintas parroquias miñotas y transmontanas (Sta. María de Âncora, Santiago de Romarigães, Meadela, Salamonde, Adoufe, Calvão, San Nicolau de Mesão Frio, etc. ${ }^{31}$ ), su estancia se prolonga durante varios años o incluso se convierte en definitiva.

Al trabajo de estos criados y asistentes en las parroquias rurales se suma a menudo el de otros trabajadores que, bien durante varios meses, bien con carácter más puntual para una tarea concreta, son contratados para las labores agrícolas y, en particular, para los trabajos de los olivares y,

\footnotetext{
${ }^{31}$ Véase Nota 5.
} 
sobre todo, de las viñas; estas faenas agrícolas, en particular las de la cava y de la vendimia, concentraban en la región del Alto Duero un numeroso contingente de trabajadores en su mayoría de la Terra Fria transmontana y de Galicia. Según las "signaes" de los pasaportes internos expedidos en Viana do Castelo, su edad media -la muestra reúne 52 jornaleros y labradoreses de 32,5 años; el 57,7\% del total no ha cumplido los 35 años y el 75\%, los 40 años; los mayores de 50 años suponen tan sólo el 13,4\%. De edades relativamente jóvenes, entre sus efectivos predominan los casados (50\%) frente a los solteros $(28,8 \%)$.

Debido a su frecuente empleo en los trabajos de las viñas, en los libros de "receitas" y "despesas" de las quintas durienses de la Congregación del Oratorio de Oporto se contabilizan con relativa frecuencia partidas salariales pagadas a gallegos por "asistir" durante varios meses trabajando en arrancar y carretar leña, vigilar las viñas, etc. ${ }^{32}$. Asimismo, en estos libros de contabilidad se consignan asientos salariales pagados por trabajos en los olivares y, sobre todo, en las viñas, que se van sucediendo a lo largo del año hasta la nueva vendimia, realizada en octubre. Cuadrillas de hombres son empleados para cavar los olivares $y$, con posterioridad, para varear la aceituna, que recogen mujeres y niños.

Las labores de la viña exigían efectivos laborales todavía más numerosos, que se ocupaban a lo largo de casi todo el año, salvo en el verano, de diferentes faenas: de "escavar y esmadeyrar las vinhas", de la "cava", de la "mergulha", de la "erguida", de la "redra" y, finalmente, de la vendimia ${ }^{33}$. Entre los trabajadores ocupados en estas tareas, algunas de ellas en ocasiones contratadas a destajo, se encuentran gallegos, cuyos sueldos son asentados bien de forma individual ("Joseph galego", "galego Denis", etc.), bien de forma genérica ("um gallego", "oito gallegos", etc.). Sus salarios diarios varían en función de las tareas realizadas; en la década de 1740 el más elevado, de 120 réis, era pagado a los trabajadores de la "cava", de "la

${ }^{32}$ Arquivo Distrital de Porto. Congregação do Oratório São Filipe Neri - Porto. COSFNPRT/G/B/003/Liv. 0023-15/3/72, ff. 21 (1748); 23 (1749), 166 (1748), etc.

${ }^{33}$ La naturaleza de los trabajos de las viñas y su dureza comentada por SALAVESSA, Maria Eunice Costa - Un traço cultural do Alto Douro vinhateiro. Douro. Estudos\&Documentos. 19 (2005) 191-192. 
erguida" y de "la redra", mientras que vendimiadores y vendimiadoras debían conformarse con sueldos inferiores, de 80 y 40 réis respectivamente ${ }^{34}$.

Por fin, la cantería es el último oficio ejercido por los emigrantes gallegos que privilegian los pasaportes internos portugueses. En los emitidos en Penafiel, el 34,5\% autorizan el desplazamiento de canteros; en cambio, en los expedidos en Viana do Castelo, suponen tan sólo el 2,6\% y los carpinteros, el $0,8 \%$. Sus condiciones personales son, en todo caso, difíciles de establecer debido a que no disponemos de datos suficientes sobre el particular. En consecuencia, se impone la precaución a la hora de tomar en consideración las conclusiones sobre su edad y estado. En los pasaportes emitidos en Penafiel, de los cuales diecisiete precisan la edad de transeúntes canteros, la media se presenta elevada, de 35,4 años; en cambio, en los de Viana de Castelo, con una muestra todavía más reducida (10 casos), se rebaja once años (24,2 años). De los que pasan por esta última villa el 33,3\% son solteros y el $22,2 \%$ casados, sin que se registre su estado en el $44,4 \%$ de los casos.

La expansión de la producción cerealista y vitícola por estos años y la prosperidad do sector mercantil, que coinciden con la fase de apogeo del estilo barroco en el norte de Portugal entre 1700 y 1760, impulsan una intensa actividad constructiva en los principales núcleos urbanos miñotos (Braga, Barcelos o Guimarães), que ven incrementar su población en el último tercio del siglo XVIII en un $37,6 \%$, con la consiguiente necesidad de ampliar su caserío urbano. Por ejemplo, en Braga se construye, a partir de 1725, un nuevo barrio, el de O Quinteiro, que abre cinco nuevas calles; contemporáneamente, bajo el mecenazgo de los arzobispos de la Casa de Bragança, la arquitectura religiosa y civil recibe un fuerte impulso bajo la dirección de artistas como André Soares ou Carlos Amarante, que proyectan capillas, iglesias, santuarios y casas nobles en las villas miñotas, en las que trabajan maestros y oficiales canteros gallegos. A Braga la imitan en su esfuerzo constructivo y ornamental Viana do Castelo, Barcelos, Guimarães, ciudad esta última en la que en los años 1740 e 1750 está establecido un buen número de maestros canteros gallegos que son contratados para a

${ }^{34}$ Arquivo Distrital de Porto. Congregação do Oratório São Filipe Neri -Porto. COSFNPRT/G/B/003/Liv. 0023-15/3/72, ff. 11-12; 21-22; 26-27; etc. 
construcción de edificios religiosos e civiles ${ }^{35}$. La presencia de canteros gallegos se multiplica en estos núcleos a partir de la década de 1720, pero también en las comunidades rurales, donde son contratados para la construcción asimismo de capillas, iglesias, casas, etc.

En la región del Alto Duero, los canteros trabajaban asimismo en el acondicionamiento de las terrazas y en la construcción de los muros de las viñas, una tarea que empleaba a un importante número de trabajadores. En consecuencia, aunque de forma irregular, los libros de contabilidad de las quintas durienses de la Congregación del Oratorio de Oporto contabilizan partidas salariales de "pedreiros", algunos de ellos gallegos, empleados precisamente en "levantar paredes y sapadas de vinhas", en hacer "paredes y calços" $\mathrm{y}$, finalmente, en construir o conservar edificios de producción (almacenes, lagares, bodegas) $^{36}$. La ampliación de las tierras de viñedo exigía igualmente de la colaboración de un elevado número de trabajadores; en concreto, en la plantación de la nueva viña, en 1751, en el monte de Paredeyta trabajaron 1.385 jornaleros y 364 canteros, parte de ellos gallegos $^{37}$. Su salario diario, de 120 réis en los años 1750, se equiparaba al de los jornaleros agrícolas contratados para las labores más pesadas (cava, erguida, etc.).

Pero, los maestros de cantería gallegos llegados a la región del Alto Duero, al modo de sus colegas que trabajaban en la provincia miñota, diversificaban también su oferta de empleo, según confirman las escrituras de obligación de obras de la segunda mitad del siglo XVIII, contratando obras civiles y religiosas; en concreto, se encargan de la construcción de puentes, de fuentes (Fonte Real de San Salvador de Penaguião), de "casas de residencia" de distintas feligresías (Sta. Comba de Souto Maior, San Martinho de Mateus, etc.), de casas de quintas durienses, de almacenes (San Mamede de Foz Tua) y, finalmente, también de la edificación y

${ }^{35}$ VIEIRA BRAGA, Alberto - Mestres de pedrería..., cit., p. 397-408.

${ }^{36}$ A.D.P., Congregação do Oratório São Filipe Neri -Porto. COSFNPRT/G/B/003/Liv. 0023-15/3/72, f. 19(1747); f. 27 (1751); f. 166 (1748), etc.

${ }^{37}$ Ibídem, f. 280. 
remodelación de iglesias, capillas y sacristías (Afonsim, Lamares, Nogueira, Pendilhe, Piães, etc.) en los distritos de Vila Real y de Lamego ${ }^{38}$.

A modo de conclusión, puede afirmarse que, por su información plural, siempre debidamente complementada con otras fuentes (registros hospitalarios, archivos parroquiales, etc.), los pasaportes internos, pese a su implantación tardía en el tiempo, a su falta de continuidad temporal y a la irregularidad en sus registros, constituyen una fuente documental excepcional para el análisis de de la emigración gallega a Portugal, en particular para conocer las condiciones personales - sexo, estado y edad y las ocupaciones profesionales de los emigrantes: Su información es todavía más amplia porque asimismo permite conocer el plazo de duración de las estancias, el mes en que se viaja y, finalmente, el destino y, en ocasiones, incluso el itinerario de su viaje.*

${ }^{38}$ ALVES, N. Ferreira; ALVES, Joaquim Jame Ferreira - Nótulas de história da arte: noticias sobre alguns artistas e artífices dos séculos XVII e XVIII. Museu. IV serie, 3 (1995) 209-220; ALVES, Alexandre - Artistas y Artifices nas Dioceses de Lamego e Viseu. Viseu, 2001, vol. I, p. 62-63, 149, 153, 179, 274, 276, 281, etc.

El presente trabajo de investigación fue realizado durante una estancia de investigación en el Centro de Estudos das Migrações e das Relações Interculturais (CEMRI) de la Universidade Aberta de Lisboa, a cuya Investigadora Coordinadora Profesora Catedrática Da Maria Beatriz Rocha-Trindade agradezco su acogida y su inestimable colaboración. La financiación de la estancia fue cubierta con una beca de investigación concedida por la Dirección Xeral de Investigación, Desenvolvemento e Innovación, de la Xunta de Galicia y, asimismo, con fondos de la Acción Integrada "Movilidades: sociedades, productos, cultura (siglos XVII-XX)", del Ministerio de Ciencia e Innovación (PT2009-0034. Subprograma: Acciones Integradas). 